DOI https://doi.org/10.15589/znp2020.2(480).6

УДК 621.431

\title{
TO THE QUESTION INFLUENCE OF EXCESS AIR COEFFICIENT ON INDICATOR EFFICIENCY OF ICE CYCLE
}

\section{ДО ПИТАННЯ ВПЛИВУ КОЕФІЦІЕНТА НАДЛИШКУ ПОВІТРЯ НА ІНДИКАТОРНИЙ КОЕФІЦІЕНТ КОРИСНОЇ ДІЇ ЦИКЛУ ДВИГУНІВ ВНУТРІШНЬОГО ЗГОРЯННЯ}

\author{
Vasyl S. Nalyvaiko ${ }^{1}$ \\ nadiia.pogybko@nuos.edu.ua \\ Viktoriia S. Khomenko² \\ khomenkovictoria93@gmail.com \\ ORCID: 0000-0001-5813-6902 \\ Roman Yu. Avdiunin ${ }^{2}$ \\ roman021187@gmail.com \\ ORCID: 0000-0003-0798-8077
}

В. С. Наливайко ${ }^{1}$, канд. техн. наук, професор

В. С. Хоменко ${ }^{2}$, викладач

Р. Ю. Авдюнін ${ }^{2}$, викладач

\author{
${ }^{1}$ Admiral Makarov National University of Shipbuilding, Mykolaiv \\ ${ }^{2}$ Начіональний університет кораблебудування імені адмірала Макарова, м. Миколаӥв \\ ${ }^{2}$ Kherson Branch of the Admiral Makarov National University of Shipbuilding, Kherson \\ ${ }^{2}$ Херсонська філія Національного університету кораблебудування імені адмірала Макарова, м. Херсон
}

\begin{abstract}
The proposed article is devoted to finding opportunities to further improve the efficiency of internal combustion engines (ICE) at a time when the main opportunities for this are almost exhausted. The search for ways to improve the economic performance of internal combustion engines usually began with a study of the indicator cycle of the engine.

In this paper, the aim is to propose a method of research in which it is possible to identify how a particular indicator or factor affects the indicator efficiency of the cycle.

The main factor influencing the magnitude and nature of the change in indicator efficiency ( $\eta$ i) is the coefficient of excess air $(\alpha)$.

Undoubtedly, the use of mathematical modeling is indisputable to confirm the advantages of modeling over outdated calculation methods. With the advent of electronic computers, the high complexity of computational work ceased to be a problem and began the process of improving methods based on the creation of computational models of the workflow. To solve the problem of improving the efficiency of the internal combustion engine developed a thermodynamic mathematical model that allows you to assess the impact of various factors on the indicator efficiency of the engine. It is most expedient to consider separately the influence of the coefficient of excess air $(\alpha)$ on the indicator efficiency ( $\eta$ i) during modeling.

The article considers the possibility of creating and practical use of a mathematical model of the processes that occur in internal combustion engines during their operation.

The scientific novelty is to study one of the possible cases - "modeling of the indicator cycle of the engine" to determine the effect of excess air ratio $(\alpha)$ on the change of the indicator efficiency ( $\eta \mathrm{i})$. The paper presents the complete process from model creation to the final result.

Comparison of the results obtained during the simulation with the results of bench tests of real engines shows that they coincide, both in numerical values and in shape. This indicates that the mathematical model is created correctly.

The practical significance lies in the fact that the presented mathematical model can be recommended as a tool for research to find possible ways to increase the indicator efficiency of the internal combustion engine cycle.

Key words: internal combustion engines; efficiency; mathematical model; excess air ratio' separate indicator cycle.
\end{abstract}

Анотація. Запропонована стаття присвячена знаходженню можливостей подальшого підвищення економічності двигунів внутрішнього згоряння (ДВ3), тоді як основні можливості для цього практично вичерпано. Пошук шляхів покращення економічних показників двигунів внутрішнього згоряння зазвичай починався з дослідження індикаторного циклу двигуна.

У роботі поставлена мета запропонувати такий спосіб дослідження, за якого можна виявити, як окремий показник або чинник впливає на індикаторний коефіцієнт корисної дії циклу. 


\section{ЕНЕРГЕТИЧНЕ МАШИНОБУДУВАННЯ №2 2020}

Основним із головних факторів, який впливає на величину і характер зміни індикаторного коефіцієнта корисної дії $\left(\eta_{\mathrm{i}}\right), \epsilon$ коефіцієнт надлишку повітря $(\alpha)$.

Без сумніву, використання математичного моделювання $\epsilon$ незаперечним для підтвердження переваг моделювання перед застарілими методами розрахунків. 3 появою електронних обчислювальних машин висока трудомісткість розрахункових робіт вже не $є$ проблемою, почався процес удосконалення методик на основі створення розрахункових моделей проходження робочого процесу.

Для вирішення проблеми підвищення економічностідвигуна внутрішньогозгоряння розроблена термодинамічна математична модель, що дозволяє оцінювати вплив різних чинників на індикаторний коефіцієнт корисної дії двигуна. Найбільш доцільно під час моделювання розглядати окремо вплив коефіцієнта надлишку повітря $(\alpha)$ на індикаторний коефіцієнт корисної дії $\left(\eta_{\mathrm{i}}\right)$.

У статті розглянуто можливість створення та практичного використання математичної моделі проходження процесів, які виникають у двигунах внутрішнього згоряння під час їх роботи.

Наукова новизна полягає у проведенні дослідження одного з можливих випадків - «моделювання індикаторного циклу двигуна» - з метою визначення впливу коефіцієнта надлишку повітря ( $\alpha$ ) на зміну індикаторного коефіцієнта корисної дії $\left(\eta_{\mathrm{i}}\right)$. У роботі представлено повний процес від створення моделі до кінцевого результату.

Зіставлення результатів, отриманих під час моделювання, з результатами стендових випробувань реальних двигунів показує, що вони збігаються як за чисельним значенням, так і за формою. Це свідчить про те, що математична модель створена правильно.

Практична значимість полягає в тому, що представлена математична модель може бути рекомендована як інструмент проведення науково-дослідних робіт для знаходження можливих шляхів підвищення індикаторного коефіцієнта корисної дії циклу двигуна внутрішнього згоряння.

Ключові слова: двигуни внутрішнього згоряння; індикаторний коефіцієнт корисної дії; математична модель; коефіцієнт надлишку повітря; відокремлений індикаторний цикл.

\section{ПОСТАНОВКА ЗАДАЧІ}

У сучасних двигунів внутрішнього згоряння (далі ДВЗ) економічна ефективність збільшилась і за питомою витратою палива досягла $0,165 \ldots 0,155$ (кг/кВт·год), що значно випереджає ефективність існуючих інших типів теплових двигунів. Такого значного покращення паливної економічності в найближчі роки не варто очікувати. Однак деякі можливості зниження питомої витрати зберігаються.

Передусім ці можливості можна знайти, якщо повернутися до індикаторного циклу.

\section{АНАЛІЗ ОСТАННІХ ДОСЛІДЖЕНЬ І ПУБЛІКАЦІЙ}

Відомі фахівці із двигунів внутрішнього згоряння, як-т Т.М. Мелькумов, Д.А. Портнов, В.А. Ваншейдт та інші, вказують на низку чинників, які можуть за певних умов вплинути на індикаторний коефіцієнт корисної дії (далі - ККД) двигуна в бік його підвищення [1, с. 195; 2, с. 29-34]. Вони експериментально довели, що зміна коефіцієнта надлишку повітря призводить до зміни індикаторного ККД. Усі дослідження виконувались на реальних двигунах.

Під час виконання робіт, пов'язаних із підвищенням економічності двигунів, уже були враховані всі чинники, що суттєво впливають на збільшення ККД. До цих чинників належать показники окремих процесів, які формують весь індикаторний цикл, параметри робочого тіла, конструктивні особливості камери згоряння, режими роботи двигунів, характерні параметри процесу подачі палива, процесу згоряння тощо.

Незважаючи на великий об'єм експериментальних робіт, їхня цінність знижується через те, що ефект отримувався за одночасного впливу всіх вищеназваних чинників. Важко було відокремити фактори, які мають найбільший вплив на величину ККД індикаторного циклу. Це $\epsilon$ недоліком проведених досліджень

\section{ВІДОКРЕМЛЕННЯ НЕ ВИРІШЕНИХ РАНІШЕ ЧАСТИН ЗАГАЛЬНОЇ ПРОБЛЕМИ}

Бажання подальшого підвищення індикаторного ККД двигунів зумовлює вивчення чинників, роль яких не настільки очевидна (чинники, пов'язані 3 індикаторним циклом). Більшість спеціалістів уважають, що кількість факторів, які можуть вплинути на індикаторний ККД, не перевищує п'яти [2, с. 33].

Але далеко не всі із цих чинників мають вагомий вплив на ККД індикаторного циклу.

Необхідно виділити чинник, який найбільше впливає на ККД. Але відразу виникає проблема - як виділити головні фактори.

Спроба такого розподілу на експериментальних стендах, де проводяться випробовування двигунів, $є$ тупиковою, оскільки під час реальних випробовувань неможливо виділити окремі фактори.

\section{МЕТА ДОСЛІДЖЕННЯ}

$\mathrm{У}$ роботі поставлена ціль запропонувати такий спосіб дослідження, за якого можна виявити вплив на ККД індикаторного циклу ізольовано для кожного чинника.

\section{МЕТОДИ, ОБ'ЄКТ ТА ПРЕДМЕТ ДОСЛІДЖЕННЯ}

Таке дослідження можливе, якщо використовувати математичну модель відокремленого індикаторного циклу двигуна. 
Математична модель розроблена на кафедрі Суднового машинобудування та енергетики Херсонської філії Національного університету кораблебудування імені адмірала Макарова. Модель дозволяє відокремити будь-який фактор, який нас цікавить, за одночасного блокування інших.

За об’єкти для дослідження взято декілька двигунів внутрішнього згоряння, для яких уже визначений вплив коефіцієнта надлишку повітря $(\alpha)$ на індикаторний ККД $\left(\eta_{\mathrm{i}}\right)$.

Розрахункові дослідження проведено на прикладі впливу коефіцієнта надлишку повітря на індикаторний ККД циклу двигуна, тому що із цього питання $\epsilon$ експериментальні дані.

\section{ОСНОВНИЙ МАТЕРІАЛ}

Фахівці із двигунів внутрішнього згоряння зазначили, що одним із чинників, які найбільш суттєво впливають на індикаторний ККД, є коефіцієнт надлишку повітря $(\alpha)$. Це підтверджується дослідженнями, які проводились на експериментальних стендах. Через значні матеріальні витрати та складності виконання таких досліджень випробування проводились тільки для обмеженої кількості двигунів [1, с. 196; 3 , с. 410-416].

У зв'язку із цим вирішено скористатись математичною моделлю відокремленого індикаторного циклу [4, с. 65-72]. Наведена схема дозволяє оцінити вплив будь-якого чинника на індикаторний ККД $\left(\eta_{\mathrm{i}}\right)$.

Випробовування цієї моделі проводиться на двигунах, для яких раніше вже виявлявся вплив коефіцієнта надлишку повітря на ККД $\left(\eta_{\mathrm{i}}\right)$.

Під час дослідження ставились такі цілі:

1. Показати якісний збіг результатів моделювання та загальновідомих даних за характером зміни індикаторного ККД.

2. Підтвердити кількісні дані, отримані під час моделювання з експериментальними даними.

Під час моделювання вирішуються одразу дві проблеми: неможливість відокремити необхідний чинник та значні матеріальні затрати [5, с. 97-103].

Технічні характеристики двигунів, для яких проводилось дослідження, наведені в табл. 1.
Нижче наведена схема, за якою виконується розрахункове дослідження.

Щоб гарантувати достовірність дослідження, необхідно для кожного двигуна дотриматися основної умови, яка полягає у збереженні незмінними всіх параметрів на всіх режимах, крім коефіцієнта надлишку повітря [6, с. 122-132]. Перехід від режиму до режиму (за $\alpha$ ) проводиться шляхом зміни тиску наддувного повітря, який визначається за формулою:

$$
p_{\kappa}=0,872 \cdot 10^{-4} \frac{g_{e} \cdot N_{e} \cdot \alpha \cdot T_{\kappa}}{D_{u}^{2} \cdot S \cdot i \cdot z \cdot n \cdot \eta_{H}}, \mu,
$$

де $\mathrm{g}_{\mathrm{e}}$ - питома ефективна витрата палива, кг/ (кВт·год);

$\mathrm{N}_{\mathrm{e}}$ - ефективна потужність, кВт;

$\alpha$ - коефіцієнт надлишку повітря;

$\mathrm{D}_{\text {ц }}$ - діаметр циліндра, мм;

$\mathrm{S}$ - хід поршня, мм;

$\mathrm{n}$ - частота обертання колінчатого валу, $\mathrm{xB}^{-1}$;

i - кількість циліндрів;

z - коефіцієнт тактності;

$\eta_{н}$ - коефіцієнт наповнення циліндра.

У цьому розрахунковому дослідженні збережені всі параметри та показники процесів постійними, крім коефіцієнта надлишку повітря.

Результати розрахунків представлені в табл. 2 .

Таблиця 2 побудована таким чином, що зміна коефіцієнта надлишку повітря забезпечується завдяки зміні тиску наддувного повітря.

Отримавши попередні дані (табл. 2), визначаємо величину індикаторного ККД за допомогою математичної моделі відокремленого індикаторного циклу [7, с. 109; 8. с. 52-56]. Програма розрахунків на ЕОМ організована так, що дає можливість водночас отримувати не тільки тиск, об'єм і температуру газів, а також і всі важливі індикаторні показники циклу (індикаторний ККД, середній індикаторний тиск, питома індикаторна витрата палива тощо).

Наведене нижче загальне рівняння цілком описує проходження індикаторного процесу за повний цикл у межах робочого об'єму (розглядається перша розрахункова ділянка):

Таблиця 1. Технічні характеристики двигунів, які використовуються в дослідженні

\begin{tabular}{|c|c|c|c|c|c|c|}
\hline Марка двигуна & 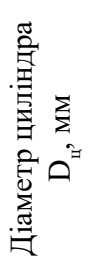 & 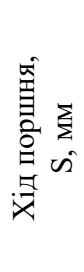 & 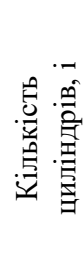 & 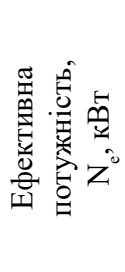 & 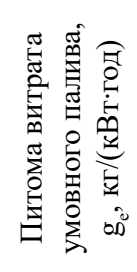 & 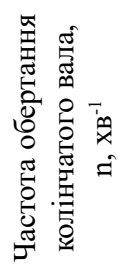 \\
\hline Wartsila L $46 / 58 \mathrm{~F}$ & 460 & 580 & 6 & 7200 & 0,170 & 600 \\
\hline 6ЧНСП18/22 & 180 & 220 & 6 & 441 & 0,208 & 1000 \\
\hline 16ЧН26/26 & 260 & 260 & 16 & 2250 & 0,204 & 1000 \\
\hline 16ЧН24/27 (Д70) & 240 & 270 & 16 & 2200 & 0,216 & 1000 \\
\hline СМД14-А & 120 & 140 & 4 & 58,8 & 0,218 & 1700 \\
\hline
\end{tabular}


Таблиця 2. Визначення величини тиску наддувного повітря для розрахунку індикаторного ККД для різних типів двигунів

\begin{tabular}{|c|c|c|c|c|c|}
\hline \multirow{2}{*}{$\alpha$} & \multicolumn{5}{|c|}{ Марка двигуна } \\
\cline { 2 - 6 } & \multirow{2}{*}{ Wartsila L46/58F } & \multirow{2}{*}{6 6ЧНСП18/22 } & 16ЧН26/26 & 16ЧН24/27 (Д70) & \multirow{2}{*}{ СМД14-А } \\
\cline { 2 - 6 } & \multicolumn{5}{|c|}{$\mathrm{p}_{\kappa}$} \\
\hline 1,5 & 0,244 & 0,189 & 0,144 & 0,084 & 0,082 \\
\hline 2 & 0,325 & 0,252 & 0,192 & 0,112 & 0,11 \\
\hline 2,5 & 0,407 & 0,315 & 0,24 & 0,168 & 0,137 \\
\hline 3 & 0,489 & 0,378 & 0,288 & 0,196 & 0,192 \\
\hline 3,5 & 0,571 & 0,441 & 0,336 & 0,224 & 0,22 \\
\hline 4 & 0,652 & 0,504 & 0,384 & 0,252 & 0,247 \\
\hline 4,5 & 0,733 & 0,567 & 0,432 & 0,28 & 0,275 \\
\hline 5 & 0,815 & 0,63 & 0,48 & 0,308 & 0,302 \\
\hline 5,5 & 0,896 & 0,693 & 0,528 & & \\
\hline
\end{tabular}

$$
\begin{gathered}
T_{i}=\frac{\Delta Q_{n i}-\Delta Q_{6 m, i}-\Delta Q_{\kappa p, i}-\Delta Q_{n p, i}}{q_{u} \cdot L \cdot\left(1+\gamma_{r}\right) \cdot \beta_{i} \cdot\left(c_{v i}-4,157 \frac{V_{i-1}-V_{i}}{V_{i}}\right)}+ \\
+\frac{q_{u} \cdot L \cdot\left(1+\gamma_{r}\right) \cdot \beta_{i-1} \cdot\left(4,157 \frac{V_{i-1}-V_{i}}{V_{i}}+c_{v, i-1}\right) \cdot T_{i-1}}{q_{u} \cdot L \cdot\left(1+\gamma_{r}\right) \cdot \beta_{i} \cdot\left(c_{v i}-4,157 \frac{V_{i-1}-V_{i}}{V_{i}}\right)}
\end{gathered}
$$

де $\Delta \mathrm{Q}_{\text {пі }}$ - кількість теплової енергії, що втрачається через днище поршня під час його охолодження мастилом, кДж;

$\Delta \mathrm{Q}_{\text {вт,i }}$ - кількість теплової енергії, що втрачається через бокову поверхню втулки на і-тій ділянці, кДж;

$\Delta \mathrm{Q}_{\text {кр,i }}$ - кількість теплової енергії, що втрачається через днище кришки на і-тій ділянці, кДж;

$\Delta \mathrm{Q}_{\text {пр,i }}$ - кількість теплової енергії, що втрачається через днище поршня за його охолодження мастилом, кДж;

$\mathrm{q}_{\text {ц }}$ - циклова подача палива, кг/цикл;

$\mathrm{L}$ - дійсна молярна кількість повітря, потрібна для спалювання 1 кг палива, кмоль/кг;

$\gamma_{\mathrm{r}}$ - коефіцієнт залишкових газів;

$\beta_{\mathrm{i}-1}, \beta_{\mathrm{i}}-$ коефіцієнт мольної зміни на початку та наприкінці розрахункової ділянки;

$\mathrm{c}_{\mathrm{v}, \mathrm{i}-1}, \mathrm{c}_{\mathrm{v}, \mathrm{i}}-$ дійсна ізохорна теплоємність газів на початку та наприкінці розрахункової ділянки, кДж/(кмоль·К);

$\mathrm{V}_{\mathrm{i}-1}, \mathrm{~V}_{\mathrm{i}}$ - об'єм робочого тіла на початку та наприкінці розрахункової ділянки, ${ }^{3}$;

$\mathrm{T}_{\mathrm{i}-1}, \mathrm{~T}_{\mathrm{i}}$ - температура газів на початку та наприкінці розрахункової ділянки, К.

Розв'язуючі рівняння (2) протягом усього циклу, отримаємо всі необхідні параметри щодо стану робочого тіла в будь-якій точці циклу.

Отже, увесь розрахунок індикаторного циклу зводиться до розв'язання одного рівняння, яке і являє собою математичну модель відокремленого індикаторного циклу двигуна.

Дамо декілька пояснень для проведення практичних розрахунків.
Рівняння (2) розв'язується методом послідовних наближень (ітерацій).

Весь індикаторний процес поділяється на досить малі (крок розрахунку $\Delta \varphi_{\kappa}=2^{\circ}$ ) розрахункові ділянки, для кожної з яких шляхом наближення проводиться ланцюговий розрахунок.

За першу розрахункову ділянки приймається та, яка стоїть першою у процесі стиснення. Для цієї ділянки початковими параметрами приймається тиск на початку стиснення $\left(\mathrm{p}_{1}=\mathrm{p}_{\mathrm{a}}\right)$ та температура робочого тіла після завершення наповнення циліндра $\left(\mathrm{T}_{1}=\mathrm{T}_{\mathrm{a}}\right)$. Як показав досвід розрахунків, за різниці температур на початку і в кінці розрахункової ділянки не більше, ніж 2 , цикл зупиняється. Після цього розрахунок проводиться для другої розрахункової ділянки тощо.

Після завершення розрахунку $\mathrm{T}_{2}$ на кожній ділянці розраховують роботу газів на цій ділянці:

$$
\Delta l_{1}=\frac{p_{1}+p_{2}}{2} \cdot\left(V_{2}-V_{1}\right)
$$

Після завершення розрахунку на всіх ділянках знаходимо повну індикаторну роботу:

$$
L_{i}=\sum_{i=180}^{i=540} \Delta l_{i} .
$$

Середній індикаторний тиск відокремленого циклу:

$$
p_{i}=\frac{L_{i}}{v_{s}} .
$$

Питома індикаторна витрата палива:

$$
g_{i}=4,58 \frac{q_{i}}{p_{i} \cdot D_{u}^{2} \cdot S} .
$$

Індикаторний ККД циклу:

$$
\eta_{i}=\frac{3600}{g_{i} \cdot Q_{H}} .
$$

Результати моделювання наведено у вигляд графічної залежності індикаторного ККД від коефіцієнта надлишку повітря для п’яти двигунів (рис. 1). 


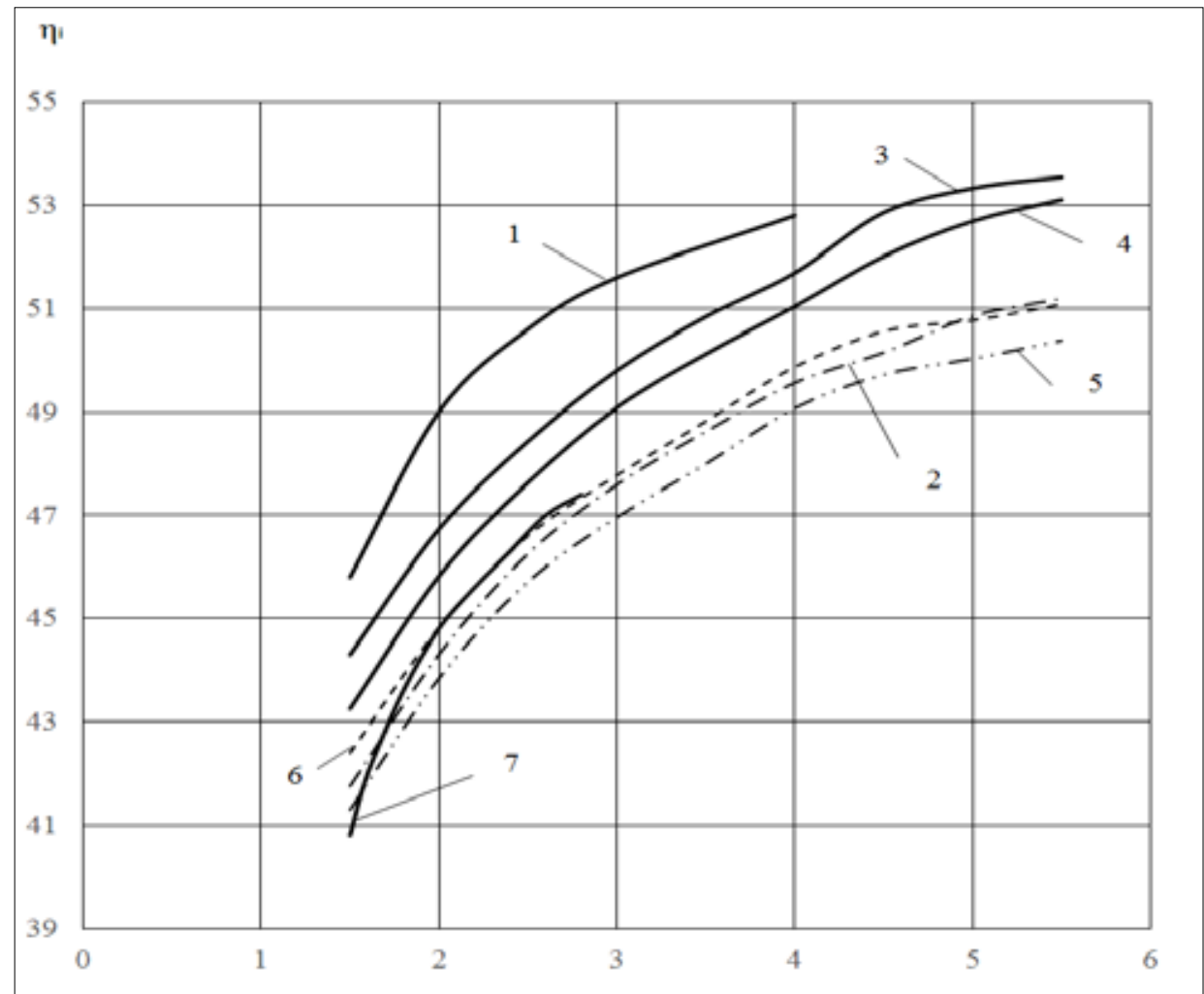

Рис. 1. Залежність індикаторного ККД циклу $\eta_{i}$ від коефіцієнта надлишку повітря $\alpha$ : 1 - результати випробування двигуна СМД-14; 2 - результати математичного моделювання відокремленого індикаторного циклу для двигуна СМД-14; 3 - результати математичного моделювання відокремленого індикаторного циклу для двигуна Wartsila L46/58F; 4 - результати математичного моделювання відокремленого індикаторного циклу для двигуна 6ЧНСП18/22; 5 - результати математичного моделювання відокремленого індикаторного циклу для двигуна 16ЧН24/27; 6 - результати математичного моделювання відокремленого індикаторного циклу для двигуна $164 \mathrm{H} 26 / 26 ; 7$ - результати випробування реального двигуна (№ 3, D = 180 мм, $\mathrm{n}=1800 \mathrm{xB}^{-1}$ )

Як видно 3 рис. 1, результати, отримані під час моделювання, практично збігаються 3 реальними результатами із знаходження індикаторного ККД реальних двигунів.

Отже, підтверджується правильність створення математичної моделі відокремленого індикаторного циклу. Це дозволяє отримати результати зміни індикаторного ККД $\left(\eta_{\mathrm{i}}\right)$ від кута повороту колінчатого вала ще на стадії ескізного проєктування двигунів.

\section{ОБГОВОРЕННЯ ОТРИМАНИХ РЕЗУЛЬТАТІВ}

Результати розрахункового дослідження за допомогою математичної моделі відокремленого індикаторного циклу й експериментальні дані, отримані на реальних двигунах, практично збігаються, як за формою отриманих залежностей, так і за чисельними значеннями зміни індикаторного ККД. Це підтверджує правильність побудови математичної моделі. Запропонований метод розрахунків дозволяє отримувати рішення під час проєкту- вання для таких величин, які неможливо розрахувати за допомогою відомих розрахункових методів.

Представлена схема розрахункового дослідження дає можливість розгляду зміни будь-якого індикаторного параметра окремо від інших параметрів, що неможливо за реальних випробувань двигунів.

\section{ВИСНОВКИ}

1. Розроблена математична модель показала достовірні результати розрахунку під час порівняння 3 експериментальними значеннями, що підтверджує іiї адекватність. Отримані результати можна пропонувати в інженерних розрахунках.

2. Запропонований спосіб розрахунку дає можливість обгрунтовано призначати деякі параметри ще на стадії ескізного проєктування.

3. Запропонований метод розрахунку дозволяє значно спростити ухвалення інженерних рішень під час проєктування ДВЗ. 


\section{ЕНЕРГЕТИЧНЕ МАШИНОБУДУВАННЯ № 2 - 2020}

\section{REFERENCES}

[1] Vanshejdt V.A. (1950) Teoryja dvygatelej vnutrennego sgoranyja [Theory of internal combustion engines]. Leningrad: Gosudarstvennoe yzdatel'stvo sudostroytel'noj literaturyi. [in Russian].

[2] Portnov D.A. (1963) By'strokhodny'e turboporshnevy'e dvigateli s vosplameneniem ot szhatiya [High-speed turbo-piston engines with compression ignition]. Moscow: Mashgyz. [in Russian].

[3] Djachenko V.G. (2008) Dvyguny vnutrishn'ogo zgorjannja. Teorija [Internal combustion engines. Theory]. Harkiv: NTU "HPI". [in Ukrainian]

[4] Varbanec R.A. (2008) Opredelenye fazyi nachala sgoranyja toplyva v zadachah matematycheskogo modelyrovanyja rabochego processa dvygatelej vnutrennego sgoranyja. [Determination of the phase of the beginning of fuel combustion in the problems of mathematical modeling of the working process of internal combustion engines]. Avyacyonnaja kosmycheskaja tehnyka y tehnologyja, № 2 (49), pp. 65-72. [in Russian].

[5] Kavtaradze R.Z. (2008) Teoriya porshnevy'kh dvigatelej. Speczial'ny'e glavy` : uchebnik dlya vuzov [Theory of piston engines. Special chapters: textbook for universities] Moscow: Izd-vo MGTU im. N.E. Baumana. [in Russian].

[6] Orlyn A.S., Vy'rubov D.N., Yvyn V.Y., Kruglov M.G. (1971) Dvygately vnutrennego sgoranyja [Internal combustion engines]. Moscow: Mashynostroenye. [in Russian].

[7] Khomenko V.S. (2009) Mozhlyvosti doslidzhennja robochogo procesu DVZ na pidstavi energetychnogo balansu v mezhah robochogo cylindru [Possibilities of research of the working process of the internal combustion engine on the basis of the energy balance within the working cylinder]. Zbirnik naukovikh prats’ NUK. № 6 (429). - pp. 104-113. [in Ukrainian].

[8] Nalyvajko V.S., Tkachenko S. G., Khomenko V.S., Avdjunin R.Ju (2017) Osnovy komp'juternogo proektuvannja DVZ : navchal'nyj posibnyk [Fundamentals of ICE computer design: a textbook]. Mykolai'v: vydavec' Torubara V.V. [in Ukrainian].

\section{СПИСОК ВИКОРИСТАНОЇ ЛІТЕРАТУРИ}

[1] Ваншейдт В.А. Теория двигателей внутреннего сгорания. Ленинград : Государственное издательство судостроительной литературы, 1950. 527 с.

[2] Портнов Д.А. Быстроходные турбопоршневые двигатели с воспламенением от сжатия. Москва : Машгиз, 1963. $342 \mathrm{c}$.

[3] Дяченко В.Г. Двигуни внутрішнього згоряння. Теорія. Харків : НТУ «ХПІ», 2008. 488 с.

[4] Варбанец Р.А., Морозов А.И., Михайлов Д.Ю. Определение фазы начала сгорания топлива в задачах математического моделирования рабочего процесса двигателей внутреннего сгорания. Авиационная космическая техника и технология. 2008. № 2 (49). С. 65-72.

[5] Кавтарадзе Р.3. Теория поршневых двигателей. Специальные главы : учебник для вузов. Москва : Изд-во МГТУ им. Н.Э. Баумана, 2008. 720 с.

[6] Двигатели внутреннего сгорания / А.С. Орлин и др. Москва : Машиностроение, 1971. 399 с.

[7] Хоменко В.С. Можливості дослідження робочого процесу ДВЗ на підставі енергетичного балансу в межах робочого циліндру. Збірник наукових праць Національного університету кораблебудування імені адмірала Макарова. 2009. № 6 (429). C. 104-113.

[8] Основи комп’ютерного проектування ДВ3 : навчальний посібник / В.С. Наливайко та ін. Миколаїв, 2017. 138 с.

(C) В. С. Наливайко, В. С. Хоменко, Р. Ю. Авдюнін Дата надходження статті до редакції: 10.06.2020 Дата затвердження статті до друку: 10.07.2020 